\title{
Intra-specific Differences in Root and Shoot Glucosinolate Profiles among White Cabbage (Brassica oleracea var. capitata) Cultivars
}

\author{
Patrick Kabouw, ${ }^{*}{ }^{\dagger}$ Arjen Biere, ${ }^{\dagger}$ Wim H. van der Putten,${ }^{\dagger \dagger}$ And \\ Nicole M. VAN DAM ${ }^{\dagger, \S}$ \\ †Department of Terrestrial Ecology, Netherlands Institute of Ecology (NIOO-KNAW), P.O. Box 40, 6666 \\ ZG Heteren, The Netherlands, and "Laboratory of Nematology, Wageningen University, \\ Droevendaalsesteeg 1, 6708 PB Wageningen, The Netherlands. ${ }^{\S}$ Current address: Institute of Water and \\ Wetland Research, Radboud University Nijmegen, P.O. Box 9010, 6500 GL Nijmegen, \\ The Netherlands.
}

\begin{abstract}
Shoot glucosinolate profiles of Brassicaceae are known to vary within species, across environmental conditions, and between developmental stages. Here we study whether root profiles follow the intraspecific, environmental, and developmental variation observed for aerial parts in white cabbage cultivars. We also assess whether greenhouse studies can be used to predict shoot and root glucosinolate concentrations and profiles in the field. Root glucosinolate profiles showed significant intra-specific variation; however, this variation was unrelated to that in shoot profiles. One of the strongest determinants of the diversity in the root profiles was 2-phenylethyl glucosinolate (gluconasturtiin). Root profiles were generally comparable between greenhouse studies and field trials, whereas shoot profiles were highly plastic. We conclude that among white cabbage cultivars, shoot glucosinolate profiles are not indicative of root profiles. We further conclude that greenhouse assessments of root glucosinolates can be reliable predictors of root glucosinolate profiles in the field due to their low plasticity.
\end{abstract}

KEYWORDS: Induced response; glucosinolates; 2-phenylethyl glucosinolate; abovegroundbelowground; plant defense; Brassica oleracea

\section{INTRODUCTION}

Brassicas are economically important crops that show high intra-specific variation in morphological and chemical traits (1). Glucosinolates (GSs), a structurally diverse group of about 120 nitrogen- and sulfur-containing secondary metabolites, are widespread within the Brassicaceae. Previous studies have shown that concentrations and profiles of GSs show considerable variation within species and that they vary with environmental conditions and developmental stage $(1-5)$. Variation in GSs has been of interest to ecologists and nutritional chemists alike. Ecological studies have investigated the effects of variation in Brassica oleracea GS concentrations and profiles on aboveground plant-insect interactions. Both generalists and specialists can be influenced by GSs $(5,6)$. Some GSs may have anticarcinogenic effects $(7,8)$, and nutritional studies have mainly focused on these GSs in the economically important aerial parts during the harvestable phase of the plants. Root GS levels, although less studied in the context of human health for which they also can be used (9), are important for resistance against soil pests and may be used for biofumigation.

*To whom correspondence should be addressed. Mailing address: Netherlands Institute of Ecology, Boterhoeksestraat 42, Post Box 40, 6666ZG Heteren, The Netherlands. Tel: +31026 4791206. E-mail address: p.kabouw@nioo.knaw.nl.
From the plant's perspective, GSs in roots and shoots share the same function, that is, defense again harmful organisms. Moreover, there is evidence for transport of GSs and their precursors through the phloem $(10-12)$, suggesting that shoots and roots exchange GSs. This implies that their levels and profiles could be correlated. However, the few studies that have addressed this correlation show that GS levels are on average 4.5 -fold higher in roots than in shoots and that the composition of the GS, is also significantly different between these plant parts $(3,13)$. Records on linkages between root and shoot GS levels and profiles are scarce and mainly focus on differences in the patterns of induction within a single plant or cultivar (14).

Only a few studies have investigated whether variation in shoot and root GS profiles and concentrations between cultivars is consistent across different environments and developmental stages. In aerial parts, GS concentrations depend on a variety of factors including temperature, time of day, water content, and nutrient supply $(6,13,15,16)$. Even under controlled greenhouse conditions, GS concentrations in leaves of Brassica species fluctuate when sown over a time period of several months, which was ascribed to abiotic seasonal changes (6). Soil characteristics like $\mathrm{pH}$ influence GS concentrations in leaves of kale (17-20). In addition, the developmental stage of the plant also affects both the concentration and the profiles of the GSs (17). Biotic interactions may alter GS profiles as well. Aboveground 
plant-animal interactions can cause upregulation of specific GSs, depending on the tissues attacked and the identity of the herbivore $(21,22)$. In $B$. oleracea, herbivory by the generalist Myzus persicae upregulates indolic GS (23), whereas damage resulting from the specialist Pieris rapae also increases aliphatic GS (24). There is especially little information on root GS.

Studies of root GSs have mainly focused on the effects of specific root GSs on soil (micro)organisms $(2,25,26)$. The best studied root GS is 2-phenylethyl GS, which on average accounts for $40 \%$ of the total GS concentration in Brassica species $(13,14)$. The 2-phenylethyl GS degradation product, 2-phenylethyl isothiocyanate, is highly toxic to a range of soil organisms, such as fungi and root-feeding nematodes $(2,14)$. Currently, plant breeders are attempting to increase the GS concentration and specifically 2-phenylethyl GS in Brassica roots (27) to apply them as biofumigants. Because the effect of 2-phenylethyl GS is concentration dependent, it is important to know how consistent root GS profiles are in response to variable conditions. Because it is easier to sample shoot tissue over time, it would be most practical for the selection process if root concentrations and profiles could be predicted from shoot samples, preferably from greenhouse trails.

Our study has two main aims. First we assess intra-specific variation in shoot and root GS concentrations and profiles in 12 different white cabbage cultivars and analyze whether there is a correlation between root and shoot GSs. Second, we examine the stability of the profiles across environments and developmental stages in a subset of the cultivars covering the range of variation present in all 12 cultivars. Our results will show how stable root and shoot GSs are under these different conditions and whether field GS concentrations and profiles can be predicted from greenhouse trials.

\section{MATERIAL AND METHODS}

Cultivar Selection. Twelve white cabbage cultivars were selected to cover a wide range of variation in either GSs or resistance/susceptibility to insect pests. These cultivars (with seed source and if known the breeder in parentheses) were Badger Shipper (Centre for Genetic Resources NL, University of Wisconsin US), Bartolo (breeder and source Bejo seeds, NL), Bewama (Plant Research International, NL), Castello (breeder and source Nickerson Zwaan, NL), Christmas Drumhead (Centre for Genetic Resources, NL), Domia (Horticulture Research International, UK), Galaxy (breeder and source Seminis, NL), Jersey Queen (Centre for Genetic Resources, NL), Langendijker Bewaar (Plant Research International, NL), Lennox (breeder and source Bejo seeds, NL), Rivera (breeder and source Bejo seeds, NL), and Stonehead (breeder and source Sakata, Japan). All varieties are hybrids or inbred lines.

Seeds were germinated for 10 days in a growth cabinet in a plastic container with glass beads and demineralized water. The growth cabinet had a day/night period of $16: 8 \mathrm{~h}$ and a temperature of $25: 15{ }^{\circ} \mathrm{C}$, respectively. Ten seedlings were transferred to $1 \mathrm{~L}$ pots filled with 1100 $\mathrm{g}$ of river sand (particle size distribution: $<125 \mu \mathrm{m}, 13 \% ; 125-250 \mu \mathrm{m}$, $83 \% ;>250 \mu \mathrm{m}, 4 \%$ ). The surface surrounding the seedlings was covered with aluminum foil to reduce evaporation. Pots were relocated to a greenhouse with the following conditions (day/night): $25 / 15^{\circ} \mathrm{C}, 16 / 8 \mathrm{~h}$, and a minimum photoactive radiation (PAR) of $225 \mu \mathrm{mol} \mathrm{m}^{-2} \mathrm{~s}^{-1}$. At regular intervals, the plants were fertilized with an increasing amount of half-strength Hoagland nutrient solution with double the amount of $\mathrm{KH}_{2} \mathrm{PO}_{4}$. In addition, the pots were weighed and supplemented with water to maintain a water content of $14 \%$ based on dry sand mass once a week. Plants were harvested 29 days after planting. Roots were rinsed with tap water and dried with filter paper, and both roots and shoots were frozen at $-20{ }^{\circ} \mathrm{C}$ within $5 \mathrm{~min}$ of harvest.

Induction Experiment. One of the important aromatic glucosinolates (2-phenylethyl GS) appeared to be absent from some of the cultivars including Galaxy (see Results). To assess whether this cultivar only lacked 2-phenylethyl GS constitutively or whether it was also unable to produce this GS after induction, we performed an additional experiment. We tested for induction of this aromatic GS in Galaxy after treatment with jasmonic acid to the roots. We only tested for induction in the roots because shoots of Brassicacea generally produce negligable amounts of this GS (14). Seeds of Galaxy were germinated on glass beads for 10 days, transferred to $1 \mathrm{~L}$ pots filled with river sand, and placed in a greenhouse under the same conditions as above. After 28 days from relocation, ten plants were treated with $2.4 \mu \mathrm{mol}(0.5 \mathrm{mg}$ ) of jasmonic acid (Sigma, St. Louis, MO) in $10 \mathrm{~mL}$ of $0.1 \%$ Triton (Sigma) injected near the root-shoot interface in the sand. Ten control plants were treated with the same amount of $\mathrm{HCl}$ to control for $\mathrm{pH}(=4)$ effects. Seven days after treatment, all plants were harvested, and their roots were washed and frozen at $-20^{\circ} \mathrm{C}$ as above.

Greenhouse Study. Based on previous experiments and results obtained from this study, the Lennox, Rivera, Christmas Drumhead, and Badger Shipper cultivars were selected to cover a substantial range of observed GS variation (28). Seeds were germinated on glass beads for 10 days. Ten seedlings per cultivar were transferred to $2 \mathrm{~L}$ pots filled with 2000 $\mathrm{g}$ of a sieved (5 mm mesh) and mixed loamy, sandy mineral soil from Mossel (Planken Wambuis; $52.06^{\circ}$ north, $5.75^{\circ}$ east, The Netherlands; $\mathrm{N}=0.13 \%, \mathrm{C}=2.1 \%, \mathrm{C} / \mathrm{N}=16.7$; particle size distribution: $<2 \mu \mathrm{m}$, $3 \% ; 2-63 \mu \mathrm{m}, 17 \%$; $>63 \mu \mathrm{m}, 80 \%$ ) before relocation to the greenhouse. This soil was known to contain a variety of beneficial and harmful soil organisms (29). Plants were supplied twice with nutrients (half-strength Hoagland nutrient solution with double the amount of $\mathrm{KH}_{2} \mathrm{PO}_{4}$ ) and once a week, the pots were calibrated to achieve a soil moisture content of $19 \%$ of dry soil weight. The greenhouse conditions were as above. Roots were collected 56 days after relocation, at which time the plants had similar sizes as in the cultivar selection experiment, and washed with tap water before storage at $-20{ }^{\circ} \mathrm{C}$.

Field Experiment. The same four cultivars as above were used in a field trial. The trial started on April 28, 2008, with 2 week old seedlings and consisted of 32 plots with 49 plants of one cultivar per plot ( 8 plots per cultivar). The location of the plots was randomized. The field was located near Wageningen; $51.95^{\circ}$ north, $5.64^{\circ}$ east, The Netherlands, with the following characteristics: $\mathrm{N}=0.14 \%, \mathrm{C}=1.7 \%, \mathrm{C} / \mathrm{N}=12$; particle size distribution $<2 \mu \mathrm{m}, 5 \% ; 2-63 \mu \mathrm{m}, 76 \% ;>63 \mu \mathrm{m}, 19 \%$ (clay soil). On September 5, 130 days after germination, leaf material was collected. The third-youngest leaves of four plants per plot were removed with a scalpel and flash-frozen in liquid nitrogen. The leaf samples were transported to the lab in a plastic bag on ice and stored at $-20^{\circ} \mathrm{C}$. On the September 8 , 133 day old roots of an additional two plants per plot were harvested and transported to the laboratory on ice, where the roots were cleaned with tap water and frozen at $-20^{\circ} \mathrm{C}$. All samples were pooled per plot.

Glucosinolate Analysis. Roots and shoots were freeze-dried, and GSs were extracted from finely ground plant material $(100 \mathrm{mg})$ by boiling in $70 \% \mathrm{MeOH}$, washing twice in $1 \mathrm{~mL}$ of $70 \% \mathrm{MeOH}$, twice in $1 \mathrm{~mL}$ of MilliQ-treated water, and once in $2 \mathrm{~mL}$ of $\mathrm{NaOAC}$ before being treated for $16 \mathrm{~h}$ with $20 \mu \mathrm{l}$ arylsulfatase, which contained 24 units/g of solid product (Sigma, St. Louis, MO) on a DEAE-Sephadex A 25 (also Sigma) column. In the following days, the eluate was freeze-dried, redissolved in $1 \mathrm{~mL}$ of Milli-Q water-treated water, and filtered over a $20 \mu \mathrm{m}$ filter. Separation of the GSs was performed with a reversed phase C-18 column on a HPLC with an acetonitrile/Milli-Q-treated water gradient. GS detection was performed with a photodiode array detector with $229 \mathrm{~nm}$ as the integration wavelength. We used the correction factors at $229 \mathrm{~nm}$ from Buchner (30), the EC (31), and Brown et al. (32) to calculate the concentrations of the GSs. Desulfoglucosinolate peaks were identified by comparison of HPLC retention times and ultraviolet spectra with those of standards, which were provided by M. Reichelt, MPI Chemical Ecology, Jena (Germany), and a certified rape seed standard (Community Bureau of Reference, Brussels, code BCR-367R). Different concentrations of 2-propenyl GS (ACROS, NJ) were used as external standard and extracted following the same procedure as the plant material. GS levels were calculated on the basis of dry weight.

Statistical Analysis. Student's $t$-tests were used to analyze differences in GS levels between roots and shoots. Pearson correlations were used to analyze associations between root and shoot GS concentrations. Significance values were corrected with a Bonferroni correction $\left(\alpha^{\prime}=\alpha / n\right)$ to adjust for multiple testing. Differences in GSs between cultivars were studied using analysis of variance (ANOVA). When ANOVA assumptions could not be met, a nonparametic Kruskal-Wallis test was used. 
For all these analyses, GSs were grouped on the basis of their biosynthetic origin (aliphatic, indole, aromatic, and total). Values were transformed, if needed, to achieve normality and homogeneity of variances. Tests were performed in Statistica 8.0 (StatSoft, Tulsa, OK).

Ordination diagrams in CANOCO (Biometris, Wageningen, NL) were used to visualize the variation in profiles within and between roots and shoots. Detrended correspondence analysis was used to check the length of the gradient. Depending on the score, either principal component analysis (PCA) or correspondence analysis (CA) was used for visualization. The former appeared to be the most appropriate method for shoots, the latter for roots, and these were used accordingly. If needed, data was $\log$ transformed. Cultivar differences in both the ordination diagrams were examined by taking the sample scores of the ordination diagrams. Thereby we focused on intersample distances on the significant axes (determined by Scree plots of root CA diagrams and parallel analysis with Monte Carlo permutation tests for shoot PCA diagrams) and checking the significance with an ANOSIM on the basis of Euclidean distances in the program PAST (version 1.89) (33). Significance values were corrected with a Bonferroni correction. The overall significance was checked with a Redundancy Analysis by checking the significance between the cultivars on the first and all other axes by Monte Carlo permutation test in the program CANOCO. The similarity of the clustering between the root in the CA plot and shoot in the PCA plot was checked by examining the correlation between the two by a Mantel test. For this test, the Euclidean distances between the cultivars that were generated for the ANOSIM permutation test were compared with each other.

\section{RESULTS}

Differences in GSs between Roots and Shoots. Both roots and shoots of the 12 cultivars contained aliphatic, indole, and aromatic GSs (Table 1). Root concentrations were on average 3.6-fold higher than shoot concentrations (average root concentration $11.5 \pm 4.8 \mu \mathrm{mol} / \mathrm{g}$, average shoot concentration $3.1 \pm$ $1.7 \mu \mathrm{mol} / \mathrm{g}$, Student's $t$-test, $P<0.001)$. There was no significant correlation between root and shoot concentrations of total $(P=$ $\left.0.29, R^{2}=0.01\right)$, aliphatic $\left(P=0.12, R^{2}=0.03\right)$, or indole GSs $\left(P=0.14, R^{2}=0.02\right)$. When studied at the level of individual GSs, only two GSs showed significant correlations between shoot and root concentrations: the aliphatic 2-propenyl GS $(P<0.001$ $\left.R^{2}=0.49\right)$ and 2-phenylethyl GS, the only aromatic GS recorded in this study $\left(P=0.001, R^{2}=0.25\right)$.

Variation in the GS profiles was larger in the roots than in the shoots, as visualized in Figure 1; root samples cluster further apart than shoot samples. The GS profiles of the cultivars showed no significant correlation between root and shoots (Mantel test comparing the positions in both ordination diagrams, $P>0.1$ ). The most dominant GS in both shoots and roots was 2-propenyl GS, which made up $33.2 \%$ of the total GS concentration in shoots and $18.0 \%$ in roots. In shoots, the second most dominant GS was 3-methylsulfinylpropyl (29.1\%), the only GS that was found in higher concentrations in shoots than in roots (Figure 1). In roots, the second most dominant GS was 3-methylthiopropyl GS (16.0\%) followed by 4-methoxy-3-indolylmethyl GS (10.1\%) and 2-phenylethyl GS (9.2\%). In the shoots, 2-phenylethyl GS was only recorded in trace amounts (Table 2).

Differences in GSs between Cultivars. Shoot GS concentrations (total, indolyl, aromatic, and aliphatic) showed significant cultivar differences. In roots, both the aromatic and aliphatic GS concentrations differed significantly between cultivars, whereas the indolyl and total GS levels did not (Table 2).

To examine differences in root GS profiles between cultivars, the root GSs were plotted in a CA diagram (Figure 2A). Euclidean distances between the cultivars were calculated by taking the sample loadings on the first four axes, which explained $75.4 \%$ of the variation. The $R$ values of this analysis, obtained by ANOSIM permutation tests, are shown in Table 3 with significant values highlighted. This demonstrates that root GS profiles differ
Table 1. Glucosinolates Recorded in Root and Shoots in the Greenhouse Cultivar Selection Experiment, with Abbreviations and Trivial Name ${ }^{a}$

\begin{tabular}{|c|c|c|c|}
\hline abbreviation & trivial name & scientific name & root shoot \\
\hline
\end{tabular}

\begin{tabular}{lllrr}
\multicolumn{5}{c}{ Aliphatic } \\
IBE & glucoiberin & 3-methylsulfinylpropyl & 12 & 12 \\
SIN & sinigrin & 2-propenyl & 12 & 12 \\
RAPH & glucoraphanin & 4-methylsulfinylbutyl & 12 & 12 \\
IBV & glucoiberverin & 3-methylthiopropyl & 12 & 12 \\
ERU & glucoerucin & 4-methylthiobutyl & 12 & 9 \\
PRO & progoitrin & 2-OH-3-butenyl & 12 & 12 \\
EPRO & epiprogoitrin & 2-(S)-2-hydroxy-butenyl & 9 & 7 \\
GNA & gluconapin & 3-butenyl & 11 & 12 \\
& & Indolyl & & \\
& & & 12 & 12 \\
4OH & 4-hydroxyglucobrassicin & 4-OH-3-indolylmethyl & 12 \\
4MeOH & 4-methoxyglucobrassicin & 4-methoxy-3-indolylmethyl & 12 & 11 \\
NEO & neo-glucobrassicin & 1-methoxy-3-indolylmethyl & 12 & 12 \\
GBC & glucobrassicin & 3-indolylmethyl & 12 & 12 \\
& & & & \\
& & Aromatic & 10 & 8 \\
NAS & gluconasturtin & 2-phenylethyl & & \\
\hline
\end{tabular}

${ }^{a}$ GSs are grouped based on their biosynthetic origin. The number indicates in how many of the cultivars the glucosinolate was recorded.

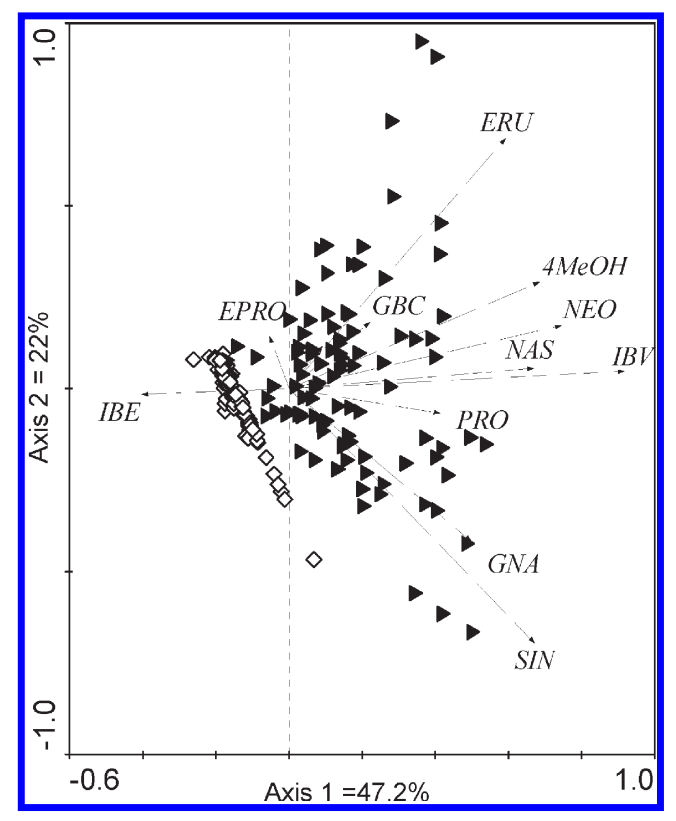

Figure 1. PCA plot of root and shoot glucosinolate profiles of 12 cabbage cultivars (for abbreviations, see Table 1). Triangles represent root samples; diamonds represent shoot samples.

significantly among cultivars even though the total concentration does not. 2-Phenylethyl GS, the only aromatic GS found in this study, makes a major contribution to these significant differences; it had the best fit to the first and third axes, and the second best fit to the second and fourth axes in the CA plot. This GS was totally absent from the cultivars Jersey Queen ( $\mathbf{J}$ in Figure 2A) and Galaxy $(G)$. Even though treatment of Galaxy plants with jasmonic acid significantly increased the total GS levels in their roots (from $7.5 \pm 2.0 \mu \mathrm{mol} / \mathrm{g}$ in the control plants to $11.7 \pm 2.1$ $\mu \mathrm{mol} / \mathrm{g}$ in the jasmonic acid treated plant, Student's $t$-test, $P<$ 0.001), 2-phenylethyl GS was still not detectable in the roots of these treated plants.

Shoot GS profiles were plotted separately in a PCA plot (Figure 2B). The first two axes explained $86.1 \%$ of the variation, 
Table 2. Glucosinolate Concentration ( $\mu \mathrm{mol} / \mathrm{g}$ dry weight) from the Greenhouse Cultivar Selection Experiment ${ }^{a}$

\begin{tabular}{|c|c|c|c|c|c|c|c|c|}
\hline cultivar & aliphatic root & indole root & aromatic root & aliphatic shoot & indole shoot & aromatic shoot & total root & total shoot \\
\hline Badger Shipper & $9.76 \pm 1.31 a, b$ & $4.05 \pm 0.10 \mathrm{a}$ & $0.05 \pm 0.03 a$ & $3.11 \pm 0.67 a, b$ & $0.76 \pm 0.11 \mathrm{a}$ & $0 \pm 0 \mathrm{a}$ & $13.85 \pm 1.84 \mathrm{a}$ & $3.86 \pm 0.74 a$ \\
\hline Bartono & $8.13 \pm 0.96 a, b$ & $2.74 \pm 0.21 a$ & $2.74 \pm 0.37 b$ & $3.43 \pm 0.61 a, b$ & $0.46 \pm 0.08 a, b$ & $0.02 \pm 0.01 a, b$ & $13.60 \pm 1.32 \mathrm{a}$ & $3.91 \pm 0.68 \mathrm{a}$ \\
\hline Bewama & $7.71 \pm 1.13 a, b$ & $2.60 \pm 0.54 a$ & $3.17 \pm 0.61 b$ & $2.78 \pm 0.27 a, b$ & $0.65 \pm 0.10 a, b$ & $0.04 \pm 0.01 a, b$ & $13.48 \pm 2.09 a$ & $3.47 \pm 0.34 \mathrm{a}$ \\
\hline Castello & $10.36 \pm 1.57 \mathrm{a}$ & $2.64 \pm 0.30 \mathrm{a}$ & $0.09 \pm 0.09 a$ & $3.80 \pm 0.53 a$ & $0.59 \pm 0.10 a, b$ & $0 \pm 0 a$ & $13.09 \pm 1.80 \mathrm{a}$ & $4.39 \pm 0.60 \mathrm{a}$ \\
\hline Christmas Drumhead & $6.47 \pm 0.87 a, b$ & $5.55 \pm 1.74 \mathrm{a}$ & $2.04 \pm 0.28 b$ & $2.04 \pm 0.40 a, b, c$ & $1.29 \pm 0.41 \mathrm{a}$ & $0.01 \pm 0 a, b$ & $14.06 \pm 1.96 \mathrm{a}$ & $3.33 \pm 0.79 a, b$ \\
\hline Domia & $4.74 \pm 0.69 a, b$ & $3.26 \pm 0.54 a$ & $2.01 \pm 0.19 b$ & $2.70 \pm 0.26 a, b$ & $0.68 \pm 0.09 a, b$ & $0.04 \pm 0 b$ & $10.01 \pm 1.08 \mathrm{a}$ & $3.41 \pm 0.32 a, b$ \\
\hline Galaxy & $7.91 \pm 1.00 a, b$ & $3.61 \pm 0.86 a$ & $0 \pm 0 a$ & $2.75 \pm 0.55 a, b, c$ & $0.50 \pm 0.09 a, b$ & $0 \pm 0 \mathrm{a}$ & $11.52 \pm 1.36 \mathrm{a}$ & $3.25 \pm 0.63 a, b$ \\
\hline Jersey Queen & $4.89 \pm 0.65 a, b$ & $3.12 \pm 0.31 a$ & $0 \pm 0 \mathrm{a}$ & $1.10 \pm 0.28 c$ & $0.46 \pm 0.16 a, b$ & $0 \pm 0 \mathrm{a}$ & $8.00 \pm 1.63 a$ & $1.56 \pm 0.40 b$ \\
\hline Langendijker Bewaar & $4.35 \pm 0.66 b$ & $3.37 \pm 0.32 \mathrm{a}$ & $0.41 \pm 0.14 a, b$ & $1.79 \pm 0.35 b, c$ & $0.51 \pm 0.15 a, b$ & $0.01 \pm 0.01 a, b$ & $8.13 \pm 0.95 a$ & $2.31 \pm 0.46 a, b$ \\
\hline Lennox & $4.65+1.06 b$ & $0.43 \pm 0.05 a$ & $1.17 \pm 0.27 a, b$ & $2.47 \pm 0.27 a, b, c$ & $0.43 \pm 0.05 a, b$ & $0.01 \pm 0 \mathrm{a}, \mathrm{b}$ & $8.07 \pm 1.63 \mathrm{a}$ & $2.90 \pm 0.30 a, b$ \\
\hline Rivera & $6.73 \pm 0.75 a, b$ & $3.03 \pm 0.32 a$ & $1.75 \pm 0.33 b$ & $2.38 \pm 0.38 a, b, c$ & $0.59 \pm 0.11 a, b$ & $0.02 \pm 0.01 a, b$ & $11.50 \pm 1.24 \mathrm{a}$ & $2.99 \pm 0.46 a, b$ \\
\hline Stonehead & $4.61 \pm 0.60 a, b$ & $2.64 \pm 0.41 \mathrm{a}$ & $1.25 \pm 0.14 a, b$ & $2.03 \pm 0.18 a, b, c$ & $0.21 \pm 0.04 b$ & $0.03 \pm 0.02 a, b$ & $8.50 \pm 1.02 a$ & $2.27 \pm 0.22 a, b$ \\
\hline
\end{tabular}

${ }^{a}$ Values are presented as mean \pm standard error. Different letters denote significant differences in glucosinolate concentrations with either one-way ANOVA or Kruskal-Wallis test of differences between the cultivars (at $P<0.05$ ).

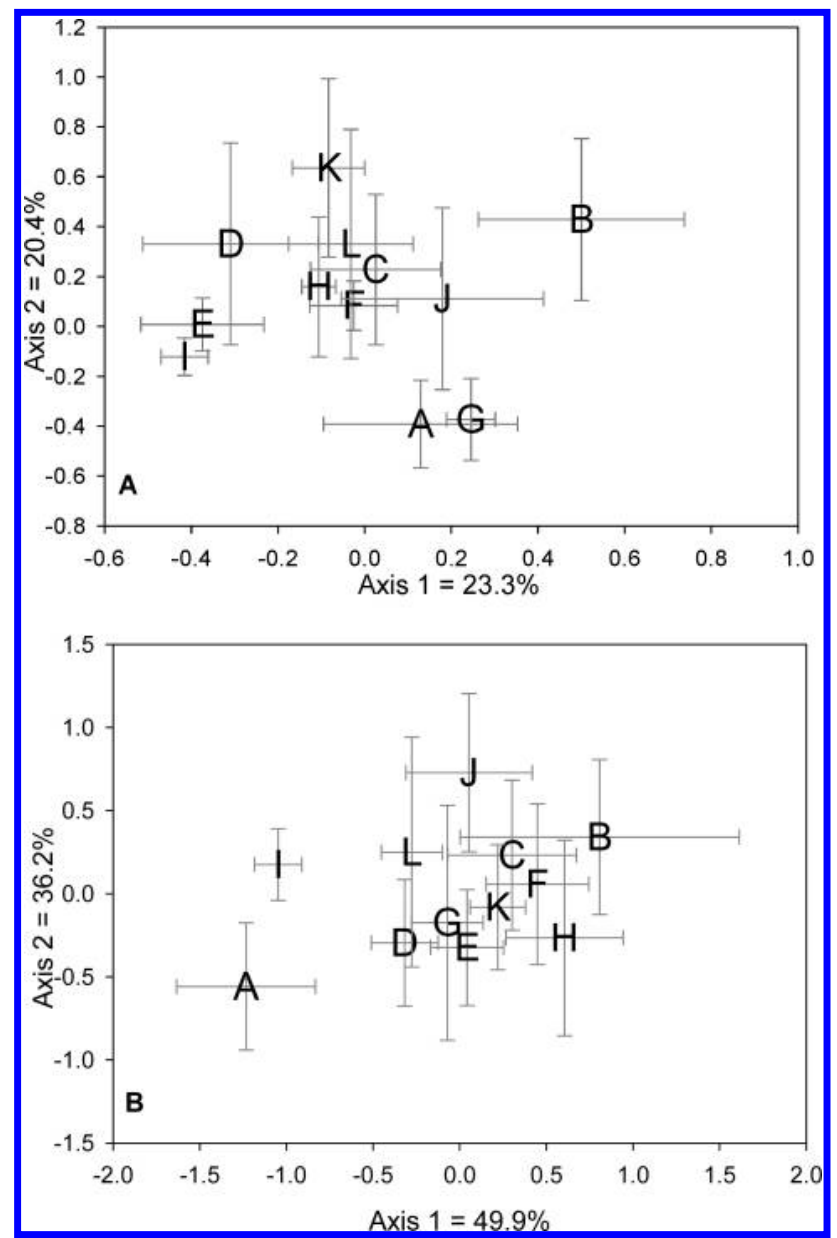

Figure 2. (A) CA ordination diagram of the first two axes of root glucosinolate profiles of the 12 cultivars based on intersample distances. The positions of the points are the mean positions of ten replicas and the associated standard deviation. Letters indicate the cultivars $(A=$ Castello, $\mathrm{B}=$ Badger Shipper $\mathrm{C}=$ Christmas Drumhead, $\mathrm{D}=$ Domia, $\mathrm{E}=$ Bewama, $\mathrm{F}=$ Rivera, $\mathrm{G}=$ Galaxy, $\mathrm{H}=$ Bartolo, I = Stonehead, J = Jersey Queen, $\mathrm{K}=$ Lennox, L = Langendijker Bewaar). (B) PCA ordination diagram of the two significant axes of shoot glucosinolate profiles of the 12 cultivars based on intersample distances.

whereas the remaining axes did not significantly explain varia tion when examined by Monte Carlo parallel analysis. $R$ values between the cultivars are listed in Table 3. Castello and Stonehead (A and I, respectively, in Figure 2B) had relatively high 3-butenyl (2.26 and $1.27 \mu \mathrm{mol} / \mathrm{g})$ and 2-propenyl (72.4 and
$81.3 \mu \mathrm{mol} / \mathrm{g}) \mathrm{GS}$ concentrations compared with the other 10 cultivars (mean $\pm \mathrm{SE}=0.50 \pm 0.14$ and $28.9 \pm 4.3 \mu \mathrm{mol} / \mathrm{g}$, respectively).

Variation in GS Profiles across Environments and due to Developmental Stage. The four cultivars that were used to represent cultivar GS variation were grown in three different environments: (1) on river sand in the greenhouse (as part of the cultivar selection experiment), (2) on sandy loam in the greenhouse (greenhouse experiment), and (3) on clay soil in the field (field trial). We used this variation in growing conditions, as well as the associated variation in developmental stages (age at harvest), to examine the consistency of their GS profiles. Since the plants not only experienced different environments but were also harvested at different ages during vegetative development (see Materials and Methods), consistency of GS patterns would indicate that GS patterns are not only conserved in the face of (a-)biotic environmental variation but also across different time points during vegetative development. The root GS profiles of these cultivars were plotted in a PCA diagram with the first axis fixed to plot the different environments and the second axis explaining $33.9 \%$ of the variation (Figure 3). The differences in root GS profiles between the cultivars grown in the three different conditions were largely consistent between the greenhouse and field experiments even though they were harvested at different time points after the start of the experiment. Badger Shipper consistently clustered apart from the other three cultivars due to its low 2-phenylethyl GS concentration. The other three cultivars remained closer together. This consistency of profiles is remarkable considering the variation in absolute concentrations among the cultivars (in both greenhouse studies, GS concentrations significantly differed from those in the field study, Table 4, Kruskal-Wallis test, $P<0.001$ ).

GS concentrations in the shoots of the four cultivars were significantly lower in the greenhouse $(6.8 \pm 4.6 \mu \mathrm{mol} / \mathrm{g})$ than in the field $(15.6 \pm 7.3 \mu \mathrm{mol} / \mathrm{g}$, Student's $t$-test, $P<0.001)$. In addition, profiles in the field were more diverged than those in the greenhouse, even though in the field we pooled samples from four different plants. Hence the variation recorded is likely to be an underestimation of the individual plant variation present in the field (Figure 4).

\section{DISCUSSION}

Here we demonstrate that profiles and total concentrations of GSs in shoots and roots of white cabbage cultivars were not significantly correlated. We further show that GS concentrations are circa three and a half-fold higher in roots than in shoots. The differences in concentrations are not due to a specific GS but more due to overall higher GS levels in roots. This seems to be a 
Table 3. R Values Obtained with ANOSIM Permutation Test on the Intersample Distances of (1) the First Four CA axes for the Roots (Values below the Diagonal), Explaining $75.4 \%$ of the Variation, and (2) the First Two PCA Axes for the Shoots (Values above the Diagonal), Explaining $86.1 \%$ of the Variation; ${ }^{a}$

\begin{tabular}{|c|c|c|c|c|c|c|c|c|c|c|c|c|}
\hline & Castello & Badger Shipper & Christmas Drumhead & Domia & Bewama & Rivera & Galaxy & Bartono & Stonehead & Jerry Queen & Lennox & Langedijker bewaar \\
\hline Castello & & $0.6651^{a}$ & $0.8236^{a}$ & $0.6106^{a}$ & $0.7815^{a}$ & $0.8377^{a}$ & $0.6099^{a}$ & $0.7596^{a}$ & 0.4118 & $0.8568^{a}$ & $0.8455^{a}$ & $0.6298^{a}$ \\
\hline Badger Shipper & $0.6778^{a}$ & & 0.0619 & $0.5131^{a}$ & $0.3667^{a}$ & 0.0004 & 0.1647 & 0.0827 & $0.5606^{a}$ & 0.0883 & 0.1642 & 0.2376 \\
\hline Christmas Drumhead & $0.6389^{a}$ & $0.4020^{a}$ & & $0.6697^{a}$ & 0.4390 & 0.0022 & 0.0645 & 0.1411 & 0.9184 & 0.0833 & 0.1714 & 0.1957 \\
\hline Domia & $0.4627^{a}$ & $0.4369^{a}$ & 0.2104 & & 0.1669 & $0.5767^{a}$ & 0.1153 & $0.5224^{a}$ & $0.5615^{a}$ & $0.6927^{a}$ & $0.5164^{a}$ & 0.1033 \\
\hline Bewama & $0.6302^{a}$ & $0.7009^{a}$ & $0.5584^{a}$ & $0.2316^{a}$ & & 0.3378 & 0.0762 & 0.2818 & $0.8593^{a}$ & $0.5920^{a}$ & 0.0764 & 0.2518 \\
\hline Rivera & $0.7276^{a}$ & $0.6380^{a}$ & $0.4458^{a}$ & $0.3838^{a}$ & $0.6100^{a}$ & & 0.1900 & 0.0082 & $0.7260^{a}$ & 0.2422 & 0.0671 & $0.3404^{a}$ \\
\hline Galaxy & 0.0402 & $0.6669^{a}$ & $0.6516^{a}$ & $0.5236^{a}$ & $0.7353^{a}$ & $0.7484^{a}$ & & 0.2258 & $0.4346^{a}$ & 0.2014 & 0.1613 & 0.01933 \\
\hline Bartono & $0.6398^{a}$ & $0.5258^{a}$ & $0.2602^{a}$ & $0.2573^{a}$ & $0.5040^{a}$ & 0.2231 & $0.6684^{a}$ & & $0.5970^{a}$ & $0.3649^{a}$ & 0.0804 & $0.3953^{a}$ \\
\hline Stonehead & $0.7867^{a}$ & $0.8076^{a}$ & $0.7020^{a}$ & $0.2016^{a}$ & $0.5111^{a}$ & $0.9304^{a}$ & $0.8351^{a}$ & $0.7478^{a}$ & & $0.8652^{a}$ & $0.9260^{a}$ & 0.3918 \\
\hline Jerry Queen & $0.2922^{a}$ & 0.1804 & 0.1611 & 0.1838 & $0.4471^{a}$ & $0.4276^{a}$ & $0.2498^{a}$ & $0.3669^{a}$ & $0.5587^{a}$ & & 0.4219 & 0.1569 \\
\hline Lennox & $0.5893^{a}$ & 0.3540 & 0.3527 & 0.1324 & $0.5031^{a}$ & $0.3798^{a}$ & $0.6073^{a}$ & $0.3551^{a}$ & $0.5733^{a}$ & 0.2393 & & $0.3753^{a}$ \\
\hline Langedijker bewaar & $0.3573^{a}$ & 0.3153 & 0.2584 & 0.0673 & $0.4102^{a}$ & $0.4169^{a}$ & $0.3324^{a}$ & $0.3102^{a}$ & $0.3851^{a}$ & 0.0926 & 0.0027 & \\
\hline
\end{tabular}

${ }^{a}$ Significant differences.

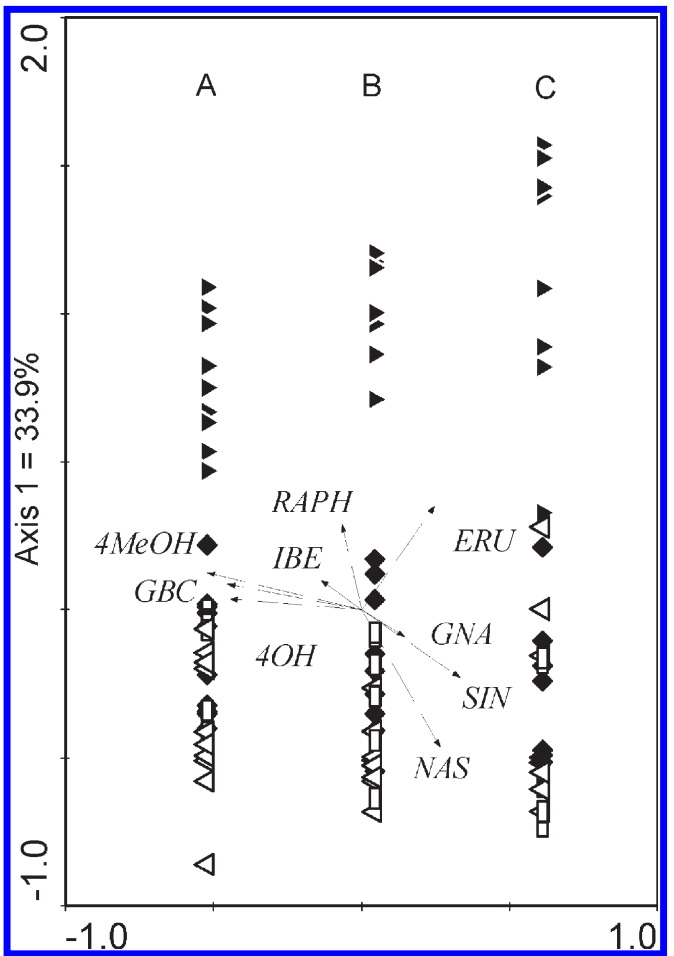

Figure 3. PCA plot of root glucosinolate profiles from the four selected cultivars: (A) greenhouse cultivar selection experiment on sandy soil; (B) greenhouse study on mixed loamy, sandy mineral soil; (C) field study; rectangles, Rivera; open triangles, Lennox; diamonds, Christmas Drumhead; filled triangles, Badger Shipper. For abbreviations of the GSs, see Table 1.

Table 4. Root Glucosinolate Concentrations ( $\mu \mathrm{mol} / \mathrm{g}$ dry weight) over the Different Environments ${ }^{a}$

\begin{tabular}{lccc}
\hline & $\begin{array}{c}\text { cultivar selection } \\
\text { experiment }\end{array}$ & $\begin{array}{c}\text { greenhouse } \\
\text { study }\end{array}$ & field study \\
\hline Badger Shipper & $13.85 \pm 1.84^{2}$ & $13.73 \pm 0.84^{1}$ & $17.59 \pm 3.16^{2}$ \\
Christmas Drumhead & $14.06 \pm 1.96^{1}$ & $7.09 \pm 0.76^{4}$ & $13.66 \pm 2.65^{4}$ \\
Rivera & $11.50 \pm 1.24^{3}$ & $7.26 \pm 0.86^{3}$ & $18.29 \pm 2.46^{1}$ \\
Lennox & $8.07 \pm 1.63^{4}$ & $10.36 \pm 0.63^{2}$ & $16.73 \pm 4.53^{3}$ \\
\hline
\end{tabular}

${ }^{a}$ Means of all samples per cultivar \pm standard error; superscript numbers indicate the ranking between the cultivars.

general pattern, except at early stages of development and during flowering, when GS concentrations belowground can be lower than or equal to those in aerial parts $(14,34)$. Here we did not

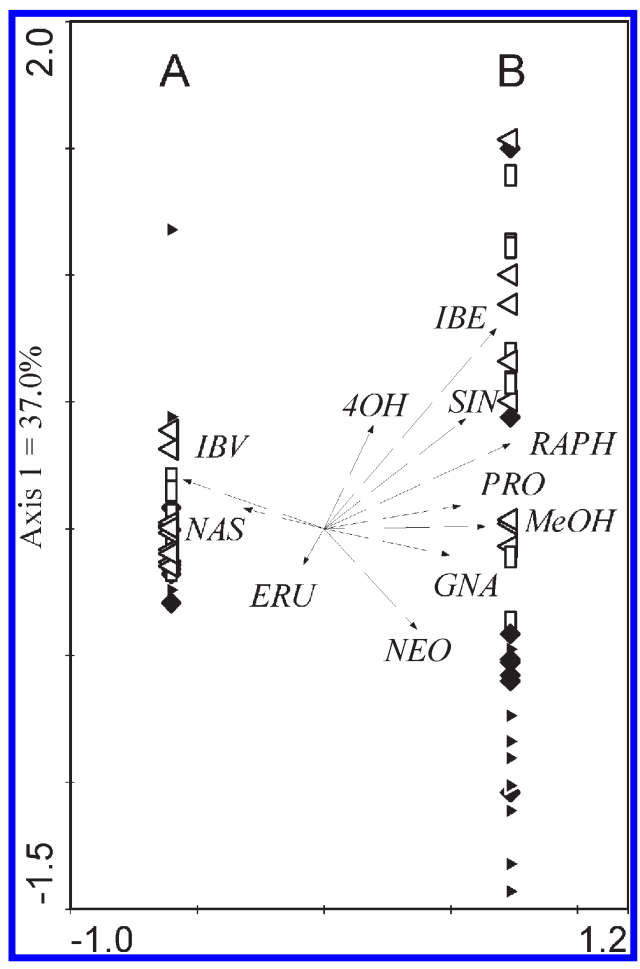

Figure 4. PCA plot of shoot glucosinolate profiles from the four selected cultivars: (A) greenhouse cultivar selection experiment on sandy soil; (B) field study; rectangles, Rivera; open triangles, Lennox; diamonds, Christmas Drumhead; filled triangles, Badger Shipper. For abbreviations of the GSs, see Table 1.

analyze the concentrations during flowering or during the seedling phase because this is less relevant for white cabbage, which is normally harvested well before flowering. It should be noted that GS concentrations are commonly expressed on a tissue dry weight basis, as in our study. However, since the water content can vary between roots and shoots, the relative difference between shoot and root concentrations may therefore be different when expressed at a tissue fresh weight basis. Nevertheless, given the large magnitude of the reported difference, expression of concentrations on a different basis is not likely to qualitatively alter the conclusion that roots have higher GS concentrations than shoots, which is consistent with previous studies (14 and references therein).

The independence of root and shoot GS profiles could be of value to agricultural practice if it would have the consequence that we can independently select for root and shoot GSs. On the 
other hand, the lack of correlation between root and shoot profiles is rather unfortunate because it means that measurements of shoot GSs have limited predictive power for the less easy to measure root GS profiles. The underlying causes of the differences between shoot and root GS profiles are unclear. It has been argued that differences in root and shoot GS concentrations and profiles in wild Brassica species might be due to differential selection pressures on glucosinolates in the aboveand belowground compartment. For instance, in the soil the breakdown products of the GSs might persist longer than in the air.

Therefore, the relative effectiveness of short- vs long-lived volatile breakdown products may differ depending on whether they are produced by the shoots or the roots. The breakdown products of 2-phenylethyl GS, the main GS responsible for the diverging profiles of root and shoot, are relatively hydrophobic, which makes them less likely to be leached from the soil, and are also relatively nonvolatile, which reduces loss from the soil $(35,36)$. There might also be a physiological basis for the observed differences in root and shoot GSs, the most plausible one being that both organs have different regulation mechanisms for the GS biosynthesis (14). Several GS transcription factors are highly compartmentalized resulting is tissue specific expression (37). Whatever the underlying causes of the differences in root and shoot GS profiles are, it means that shoot GS profiles have limited predictive power for root profiles and vice versa.

Three of the twelve cultivars contained little or no 2-phenylethyl GS. Jasmonic acid induction could not alter this in the cultivar Galaxy, which indicates that not only is it constitutively absent but also it cannot be induced by a mimick of herbivore damage. This observation is in contrast with previous studies on other Brassicaceous species. In those studies, root concentrations of aromatic GSs and specifically 2-phenylethyl GS were generally higher than those recorded here and in some cases could be increased by jasmonic acid application $(38,39)$. The fact that we found variation among our cabbage cultivars indicates that it is difficult to extract general patterns from analyzing single species or cultivars. The intra-specific variation of 2-phenylethyl GS that we recorded may influence soil organisms, such as fungi and nematodes (2). For example, it has been hypothesized that the nonmycorrhizal status of Brassica species might at least in part be due to overall high levels of 2-phenylethyl $(40,41)$. Our results suggest that white cabbage cultivars with their high intraspecific variation in this GS would be a good model system to investigate effects of 2-phenylethyl GS on root pests and other soil organisms.

Roots and shoots also differed in their responsiveness to environmental conditions and developmental stage. Shoot GS profiles were highly plastic and showed considerable differences between field- and greenhouse-grown plants. This plasticity could reflect ontogenetic changes during vegetative development as well as responses to different (a)biotic conditions in the environment. Root profiles, on the other hand, were much more constant across different experiments. This was contrary to our expectation that root GS profiles would substantially differ between the greenhouse study conducted on the loamy soil, which is rich in pathogenic soil organisms (29), and the greenhouse study conducted on the more sterile sandy soil, as a result of differential induction. Also the presumed higher variability in (a)biotic conditions in the field compared with the greenhouse did not result in more variable root GS profiles in the field. As is postulated by optimal defense theory, the difference in responsiveness between roots and shoots may be a reflection of differences in their defensive strategy $(14,42)$. Although both roots and shoots are continuously challenged by herbivores and pathogens, it has been speculated that roots might be more constantly exposed to herbivory and therefore require a constantly high level of defense expression (42), whereas shoots may experience more variable biotic stresses, thus making it profitable to respond by inducible defenses, instead of allocating limited resources to constitutive defenses (14).

Our study does not allow us to disentangle effects of development stage (age at harvest) and effects of abiotic or biotic factors on GS profiles, nor was it intended to do so. But whatever the underlying causes of observed GS variation in our experiments were, we can conclude that GSs in aerial parts have limited predictive value for root GS profiles or their concentrations. Interestingly, root profiles of plants in the field could be more reliably predicted from greenhouse studies than shoot profiles, because root profiles were less plastic under different environmental conditions or were less dependent on development stage. This enhances the opportunities for ecologists or agronomists interested in the effects of specific GSs on soil ecosystems to extrapolate the results of greenhouse studies to the field. In contrast, this cannot be said for shoot GSs because we found these to be highly plastic.

\section{ACKNOWLEDGMENT}

The authors would like to thank Ciska Raaijmakers, Alwin de Witte, Martine Kos (Wageningen University), the ERGO team, and Elke Vockenhuber (University of Göttingen) for help during the experimental phase and writing.

\section{LITERATURE CITED}

(1) Hanson, P.; Yang, R.; Chang, L.; Ledesma, L.; Ledesma, D. Contents of carotenoids, ascorbic acid, minerals and total glucosinolates in leafy brassica pakchoi (Brassica rapa L. chinensis) as

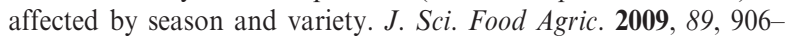
914.

(2) Potter, M. J.; Vanstone, V. A.; Davies, K. A.; Rathjen, A. J. Breeding to increase the concentration of 2-phenylethyl glucosinolate in the roots of Brassica napus. J. Chem. Ecol. 2000, 26, 1811-1820.

(3) Castro, A.; Aires, A.; Rosa, E.; Bloem, E.; Stulen, I.; Kok, L. D. Distribution of glucosinolates in Brassica oleracea cultivars. PhvtonAnnales Rei Botanica 2004, 44, 133-143.

(4) Rosa, E. A. S.; Rodrigues, A. S. Total and indivdual glucosinolate content in 11 broccoli cultivars grown in early and late seasons. HortScience 2001, 36, 56-59.

(5) Poelman, E. H.; Galiart, R.; Raaijmakers, C. E.; van Loon, J. J. A.; van Dam, N. M. Performance of specialist and generalist herbivores feeding on cabbage cultivars is not explained by glucosinolate profiles. Entomol. Exp. Appl. 2008, 127, 218-228.

(6) Gols, R.; Raaijmakers, C. E.; van Dam, N. M.; Dicke, M.; Bukovinszky, T.; Harvey, J. A. Temporal changes affect plant chemistry and tritrophic interactions. Basic Appl. Ecol. 2007, 8, 421-433.

(7) Moreno, D. A.; Carvajal, M.; Lopez-Berenguer, C.; Garcia-Viguera, C. Chemical and biological characterisation of nutraceutical compounds of broccoli. J. Pharm. Biomed. Anal. 2006, 41, 1508 1522 .

(8) Lund, E. Non-nutritive bioactive constituents of plants: Dietary sources and health benefits of glucosinolates. Int. J. Vitam. Nutr. Res. 2003, 73, 135-143.

(9) Smetanska, I.; Krumbein, A.; Schreiner, M.; Knorr, D. Influence of salicylic acid and methyl jasmonate on glucosinolate levels in turnip. J. Hortic. Sci. Biotechnol. 2007, 82, 690-694.

(10) Chen, S. X.; Petersen, B. L.; Olsen, C. E.; Schulz, A.; Halkier, B. A. Long-distance phloem transport of glucosinolates in Arabidopsis. Plant Phvsiol. 2001, 127, 194-201.

(11) Brudenell, A. J. P.; Griffiths, H.; Rossiter, J. T.; Baker, D. A. The phloem mobility of glucosinolates. J. Exp. Bot. 1999, 50, 745-756. 
(12) Merritt, S. Z. Within-plant variation in concentrations of amino acids, sugar, and sinigrin in phloem sap of black mustard, Brassica nigra (L) Koch (Cruciferae). J. Chem. Ecol. 1996, 22, 1133-1145.

(13) Rosa, E. A. S. Daily variation in glucosinolate concentrations in the leaves and roots of cabbage seedlings in two constant temperature regimes. J. Sci. Food Agric. 1997, 73, 364-368.

(14) van Dam, N. M.; Tytgat, T. O. G.; Kirkegaard, J. A. Root and shoot glucosinolates: a comparison of their diversity, function and interactions in natural and managed ecosystems. Phvtochem. Rev. 2009, 8, 171-186.

(15) Rosa, E. A. S.; Heaney, R. K.; Rego, F. C.; Fenwick, G. R. The Variation of Glucosinolate Concentration during a Single Day in Young Plants of Brassica oleracea var Acephala and Capitata. J. Sci. Food Agric. 1994, 66, 457-463.

(16) Pereira, F.; Rosa, E.; Fahey, J. W.; Stephenson, K.; Carvalho, R.; Aires, A. Influence of temperature and ontogeny on the levels of glucosinolates in broccoli (Brassica oleracea var. italica) sprouts and their effect on the induction of mammalian phase 2 enzymes. J Agric. Food Chem. 2002, 50, 6239-6244.

(17) Petersen, B. L.; Chen, S. X.; Hansen, C. H.; Olsen, C. E.; Halkier, B. A. Composition and content of glucosinolates in developing Arabidopsis thaliana. Planta 2002, 214, 562-571.

(18) Pongrac, P.; Vogel-Mikuš, K.; Regvar, M.; Tolrà, R.; Poschenrieder, C.; Barceló, J. Glucosinolate profiles change during the life cycle and mycorrhizal colonization in a $\mathrm{Cd} / \mathrm{Zn}$ hyperaccumulator Thlaspi praecox (Brassicaceae). J. Chem. Ecol. 2008, 34, 1038-1044.

(19) Velasco, P.; Cartea, M. E.; Gonzalez, C.; Vilar, M.; Ordas, A. Factors affecting the glucosinolate content of kale (Brassica oleracea acephala group). J. Agric. Food Chem. 2007, 55, 955-962.

(20) Gerendas, J.; Breuning, S.; Stahl, T.; Mersch-Sundermann, V.; Muhling, K. H. Isothiocyanate concentration in kohlrabi (Brassica oleracea L. var. gongylodes) plants as influenced by sulfur and nitrogen supply. J. Agric. Food Chem. 2008, 56, 8334-8342.

(21) Kusnierczyk, A.; Winge, P.; Midelfart, H.; Armbruster, W. S.; Rossiter, J. T.; Bones, A. M. Transcriptional responses of Arabidopsis thaliana ecotypes with different glucosinolate profiles after attack by polyphagous Myzus persicale and oligophagous Brevicoryne brassicae. J. Exp. Bot. 2007, 58, 2537-2552.

(22) Textor, S.; Gershenzon, J. Herbivore induction of the glucosinolatemyrosinase defense system: Major trends, biochemical bases and ecological significance. Phvtochem. Rev. 2009, 8, 149-170.

(23) Kim, J. H.; Jander, G. Myzus persicae (green peach aphid) feeding on Arabidopsis induces the formation of a deterrent indole glucosinolate. Plant J. 2007, 49, 1008-1019.

(24) Agrawal, A. A.; Kurashige, N. S. A role for isothiocyanates in plant resistance against the specialist herbivore Pieris rapae. J. Chem. Ecol. 2003, 29, 1403-1415.

(25) Kirkegaard, J. A.; Sarwar, M.; Wong, P. T. W.; Mead, A.; Howe, G.; Newell, M. Field studies on the biofumigation of take-all by Brassica break crops. Aust. J. Agric. Res. 2000, 51, 445-456.

(26) Schreiner, R. P.; Koide, R. T. Mustards, mustard oils and mycorrhizas. New Phvtol. 1993, 123, 107-113.

(27) Gimsing, A. L.; Kirkegaard, J. A. Glucosinolates and biofumigation: Fate of glucosinolates and their hydrolysis products in soil. Phvtochem. Rev. 2009, 8, 299-310.

(28) Poelman, E. H.; Broekgaarden, C.; Van Loon, J. J. A.; Dicke, M. Early season herbivore differentially affects plant defence responses to subsequently colonizing herbivores and their abundance in the field. Mol. Ecol. 2008, 17, 3352-3365.

(29) Wurst, S.; van Beersum, S. The impact of soil organism composition and activated carbon on grass-legume competition. Plant Soil 2009, $314,1-9$.

(30) Buchner, R., Approach to determination of HPLC response factors for glucosinolates; Martinus-Nijhoff Publishers: Dordrecht, The Netherlands, 1987; pp 50-58.

(31) E.C. 1990. Oil seeds - determination of glucosinolates High Performance Liquid Chromatography. Official Journal of the European Communities L. 170/28. Annex VIII: 03.07.27-03.07.34.

(32) Brown, P. D.; Tokuhisa, J. G.; Reichelt, M.; Gershenzon, J. Variation of glucosinolate accumulation among different organs and developmental stages of Arabidopsis thaliana. Phvtochemistrv 2003, 62, 471-481.

(33) Hammer, Ø.; Harper, D. A. T.; Ryan, P. D., 2001. Past: Paleontological Statistics Software Package for Education and Data Analysis, Palaeontol. Electron. 4(1): 9pp. http://palaeo-electronica.org/2001_1/ past/issue1_01.htm.

(34) Kirkegaard, J.; Sarwar, M. Biofumigation potential of brassicas. Plant Soil 1998, 201, 71-89.

(35) Laegdsmand, M.; Gimsing, A. L.; Strobel, B. W.; Sorensen, J. C.; Jacobsen, O. H.; Christian, H.; Hansen, B. Leaching of isothiocyanates through intact soil following simulated biofumigation. Plant Soil 2007, 291, 81-92.

(36) Sarwar, M.; Kirkegaard, J. A.; Wong, P. T. W.; Desmarchelier, J. M. Biofumigation potential of brassicas - III. In vitro toxicity of isothiocyanates to soil-borne fungal pathogens. Plant Soil 1998, 201, 103-112.

(37) Gigolashvili, T.; Yatusevich, R.; Rollwitz, I.; Humphry, M.; Gershenzon, J.; Flugge, U. I. The plastidic bile acid transporter 5 is required for the biosynthesis of methionine-derived glucosinolates in Arabidopsis thaliana. Plant Cell 2009, 21, 1813-1829.

(38) van Leur, H.; Raaijmakers, C. E.; van Dam, N. M. A heritable glucosinolate polymorphism within natural populations of Barbarea vulgaris. Phvtochemistrv 2006, 67, 1214-1223.

(39) Ludwig-Müller, J.; Schubert, B.; Pieper, K.; Ihmig, S.; Hilgenberg, W. Glucosinolate content in susceptible and resistant chinese cabbage varieties during development of clubroot disease. Phvtochemistrv 1997, 44, 407-417.

(40) Vierheilig, H.; Bennett, R.; Kiddle, G.; Kaldorf, M.; Ludwig-Muller, J. Differences in glucosinolate patterns and arbuscular mycorrhizal status of glucosinolate-containing plant species. New Phvtol. 2000, 146, 343-352.

(41) Olivier, C.; Vaughn, S. F.; Mizubuti, E. S. G.; Loria, R. Variation in allyl isothiocyanate production within Brassica species and correlation with fungicidal activity. J. Chem. Ecol. 1999, 25, 2687-2701.

(42) Karban, R.; Agrawal, A. A.; Thaler, J. S.; Adler, L. S. Induced plant responses and information content about risk of herbivory. Trends Ecol. Evol. 1999, 14, 443-447.

Received for review August 14, 2009. Revised manuscript received November 13, 2009. Accepted November 14, 2009. This research was funded by ERGO Grant No. 838.06.012 of The Netherlands Organization for Scientific Research. Publication 4664 Netherlands Institute of Ecology (NIOO-KNAW). 